\title{
La Orfandad del Hombre en los Poemas Humanos de César Vallejo
}

$\mathbf{A}^{\mathrm{N}}$ un artículo sobre el poeta peruano, Jorge Campos observa: L "...la indefensión del niño se mantiene en algunos adultos. Por ejemplo, en el que se llamó César Vallejo". 1 Vallejo siempre identificaba la felicidad con el ambiente amoroso y protector de la familia. Al producirse la dispersión de ésta el hogar quedó disuelto. Además, con la muerte de su madre llegó a sentirse huérfano, abandonado en un mundo hostil, sin amor ni protección. Esta experiencia personal influyó en su visión poética del hombre, llevándole a concebir la orfandad como la condición humana. En este artículo nos proponemos examinar algunos. de los factores que constituyen la orfandad del hombre en los Poemas bumanos de Vallejo.

La poesía de Vallejo, o mejor dicho, una gran parte de su poesía, recuerda Les pensées de Pascal por su insistencia en la miseria del hombre, y el hombre vallejiano tiene mucho en común con el roseau pensant del gran escritor francés. En "Los dados eternos" (IOI) el poeta llora por ser como es, una pobre criatura insignificante, cuya única grandeza consiste en su facultad de pensar y cuya única defensa está en que no ha sido creado a imagen de Dios, sino que es simplemente un miserable trozo de barro:

Dios mío, estoy llorando el ser que vivo...

pero este pobre barro pensativo

no es costra fermentada en tu costado. ${ }^{2}$

1 Jorge Campos, "Vallejo-Abril", Insula, Madrid No 171, 1961, p. 11.

2 César Vallejo, Los beraldos négros, Editora Perú Nuevo, Lima, 1961, p. 101. La misma edición ha sido utilizada en el caso de Trilce (señalado por la abreviación Tr) y Poemas bumarnos. Si no hay otra indicación, todas las referencias son a Poemas bumanos, ya que este estudio se basa sobre todo en este libro. 
En "Dos niños anhelantes" (88) el hombre aparece como "la eminente lombriz aristotélica" y tiene "el orgullo grave de la célula". Tiene toda la insignificancia de los animales más pequeños y de las partículas más pequeñas. Aunque su inteligencia - que llega a su apogeo en personajes eminentes como Aristóteles- le permite alcanzar cierta grandeza, en última instancia es la resignación estoica con que soporta su miseria la que le otorga dignidad.

A través de Poemas bumanos Vallejo insiste y vuelve a insistir en la pequeñez e insignificancia del hombre. Pregunta si es bastante grande para ser visto:

¿Me percibes, animal?

¿me dejo comparar como tamaño? (46)

Habla de una persona tan pequeña que se pisa a sí misma:

Tan pequeña es, acaso, esa persona, que hasta sus propios pies así la pisan? (107)

En "El alma que sufrió de ser su cuerpo" (97) el poeta hace un diag. nóstico frío e implacable de la condición humana y quiere obligarle al hombre a reconocer la realidad de su situación. En el curso de la composición invoca al hombre como "pobre hombre", "amigo mío" y "hermanito". Estos epítetos son despectivos y señalan que el hombre es una pobre criatura insignificante, digna de lástima, aunque al mismo tiempo indican cierto cariño y una identificación del poeta con el hombre. Vallejo reitera la misma idea mediante una enumeración de epítetos:

desgraciado mono, jovencito de Darwin, alguacil que me atisbas, atrocísimo microbio.

Para Vallejo, conforme a las teorías de Darwin, el hombre no es sino un animal un poco más evolucionado que las otras especies. Por eso le llama mono y jovencito de Darwin. El diminutivo es otra expresión despectiva que indica lo insignificante que es el hombre. Pero también Vallejo quiere sugerir que el hombre es joven en el sentido de que, en la escala de la evolución, él es una criatura recién aparecida en la tierra y su evolución dista mucho de ser completa. Es desgraciado en cuanto su 
destino es sufrit. ${ }^{3}$ El epíteto "atrocísimo microbio" destaca otra vez la animalidad y la insignificancia del hombre, poniéndolo al nivel de la forma más elemental de la vida. En estos versos Vallejo quiere des truir el mito de que el hombre es un ser superior, dueño del universor:

El poema termina con una discusión entre el poeta y el hombre. Este se niega a aceptar el diagnóstico del poeta, se niega a ver que no es sino un animal insignificante. Entonces el poeta se compadece de él y le ofrece la mano, pero al hacerlo incurre en un lapsus linguae y le pide la pata:

¿Que no? ¿Que si, pero que no?

¡Pobre mono!... ¡Dame la pata!... No. La mano, he dicho.

Este humorismo, es en realidad, una reiteración de todo el poema. A través de la composición, Vallejo ha intentado obligarle al hombre a reconocer su condición, pero su diagnóstico ha sido rechazado. Entonces el poeta abandona sus argumentos e intenta reducir al hombre por la ironía, tratándolo de animal.

Vallejo se sirve de varios recursos para destacar la insignificancia del hombre. Emplea los nombres de animales pequeños, como mono, lombriz, hormiga, microbio, para calificar al hombre. Así el poeta dice:

Reanudo mi día de conejo. (33)

"Hasta el día en que vuelva..." ofrece dos ejemplos de la técnica de utilizar una parte para designar un todo. Vallejo describe al hombre en términos de partes menudas de su cuerpo: su talón y su meñique. Otras veces el hombre se halla reducido a la partícula más minúscula de la materia: es un átomo ( 132 ) y su existencia es una realidad molecular. (IoI En "De disturbio en disturbio...", (73) donde el hombre aparece como

3 También se puede interpretar la palabra "desgraciado" literalmente: el hombre ha pasado de un estado de gracia o felicidad a un estado de des-gracia. o miseria. El hombre ha evolucionado en cierto sentido, pero esta evolución representa una desgracia para él en cuanto ha pasado de un estado primitivo en que vivía una vida libre, natural, espontánea, en armonía con su medio, a su estado actual en que, por haber tomado conciencia de sí mismo y de su posición en el universo, se ha dado cuenta de su insignificancia y su miseria y se siente extraño al mundo en que vive.

4 Dentro de la enumeración, el epíteto "alguacil que me atisbas" introduce un concepto nuevo. El poeta no puede escapar al hombre porque éste es como un guardia que le vigila a cada momento. Por más animal y más insignificante que sea el hombre, el poeta no puede sentirse indiferente: se siente ligado a él, siente cierta responsabilidad, y esta responsabilidad le lleva a una preocupación constante por la situación del hombre. 
un "compañero de cantidad pequeña" y un "hombre con taco" - un ser tan pequeño que necesita tacones-, los diminutivos bombrecillo y bombrezuelo subrayan su pequeñez.

No sólo el hombre es pequeño e insignificante, sino que también es frágil e indefenso. En un poema Vallejo pregunta "por qué, / cejón, inhábil, veleidoso, hube nacido / gritando" (35), y en otro afirma que el hombre "nació muy pequeñito" (68). El hombre nace delicado, indefenso, mal dotado para la vida. Nace llorando porque intuye que el mundo en que lo abandonan es hostil. El ombligo, la cicatriz que señala la separación del niño de la madre, es el simbolo de este abandono que lo angustia y que nunca llega a comprender:

a tu ombligo interrogas: ¿dónde? ¿cómo? (98)

Otros poemas describen la vida como una "pila bautismal" (3,I) y al hombre como un "hijo mortal" (64): la vida del hombre es un estado perpetuo de debilidad, de indefensión, de dependencia; el hombre nunca deja de ser un niño expuesto al peligro y necesitado del amor y protec: ción de una madre. Por eso Coyné observa que en la poesía de Vallejo "el hombre no tiene más remedios de defensa que el niño de otrora". 5 Pero el hombre es "el que ya no tecuerda su niñez" (80) : ya no goza de la protección maternal que conoció de niño. Por eso el poeta habla de "esta mayoría inválida de hombre" $(T r, 49)$ y "mi mayoría en el dolor sin fin" (Tr, 68). La condición del hombre es la del huérfano.

$\mathrm{El}$ hombre vallejiano vive en la soledad, aislado de sus semejantes. Esta soledad se refleja en la forma de las composiciones, que en general son monólogos o diálogos. En los monólogos el poeta, ensimismado, medita acerca de su situación. En los diálogos habla con otra persona, pero su interlocutor ni contesta ni comprende, ni siquiera la escucha. Se queda parado, mirándolo, sin proferir palabra:

No respondes y callado me miras. (47)

En Poemas humanos el poeta no tiene ningún contacto ni comunicación con nadie.

Una serie de poema tratan del tema del desplazada, del hombre que vive al margen de la sociedad. A veces se trata de un desplazado social y económico. El hambriento de "La rueda del hambriento": (40)

5 André Coyné, César Vallejo y su obra poética, Ed. Letras Peruanas, Lima, 1958, p. 193. 
pide socorro, pero sus ruegos dan contra un muro de silencio. Repite su ruego, subrayando que está hablando en español:

$$
\text { pero dadme / en español / algo... }
$$

Es como si fuera un extranjero en un país donde nadie le comprende. El indigente de "París, octubre I936" (60) es un paria rechazado por la sociedad y condenado a vivir en una soledad absoluta:

De todo esto yo soy el único que parte.

Hasta en medio de una muchedumbre se siente solo: su "semejanza humana" es "rodeada de gente, sola, suelta". El desgraciado se siente aislado en su miseria, aunque sabe que hay muchos otros pobres en la misma situación que él:

¡Con cuántos doses, ay! ¡estás tan solo! (II6)

En otros poemas se trata de un desplazado moral, de un hombre para quien la vida ha perdido su sentido y que ya no goza de la existencia como otras personas. En "Altura y pelos". (I24) el poeta afirma su, incapacidad para participar en la rutina diaria de los demás. En "Aniversario" (I I9) se siente perseguido por una fatalidad que le priva de la felicidad de que gozan los otros.

El hombre vallejiano es un "hombre solo" (130) condenado a "sollozar a solas" (29): su destino es sufrit en el aislamiento sin el consuelo ni el apoyo de la compañía de otros. "Algo te identifica..." (I49) afirma que hay una barrera que separa a los hombres unos de otros:

Algo típicamente neutro, de inexorablemente neutro, interpónese entre el ladrón y su víctima. Esto, asimismo, puede discernirse tratándose del cirujano y del paciente ... ¿Qué hay de más desesperante en la tierra, que la imposibilidad en que se halla el hombre feliz de ser infortunado y el hombre bueno de ser malvado?

Esta barrera la crean las circunstancias exteriores, como herencia, medio, educación, etc., las cuales determinan la personalidad de un hombre, su situación, su vida entera. Puesto que el hombre no tiene ningún control sobre estas circunstancias, es prisionero de su situación y su personalidad. El destino del ladrón es ser ladrón y el de la víctima es ser víctima, y 
no puede ser de otra manera. E1 hombre feliz no puede ser infeliz ni el hombre bueno malo, porque las circunstancias les han señalado la felicidad y la bondad. El hombre es lo que es y no puede cambiar: no puede liberarse de los confines de su personalidad y su situación y entablar comunicación con otros. "Nómina de huesos" (I44) repite esta idea:

-Que entre él y otro hombre semejante a él, se interponga una muchedumbre de hombres como él. Y esto no fue posible.

Resulta imposible juntar un grupo de hombres parecidos y hasta es imposible encontrar dos hombres parecidos. Los hombres no pueden comunicarse porque no tienen nada en común, porque cada hombre está encerrado dentro de su propia personalidad y su propia situación y es incapaz de comprender las de otros. Los hombres son islas irremediablemente aisladas unas de otras.

Por eso el poeta no puede hacer otra cosa que lamentar su soledad. Observa que en su largo peregrinaje por la vida nunca ha estado tan solo como ahora:

... jamás, como hoy, me he vuelto, con todo mi camino, a verme solo. (87)

Siente que los hombres le dan la espalda:

Es como si se hubieran dado vuelta. (32)

No sólo no tiene nadie a su lado para prestarle apoyo, sino que hasta parece que los hombres no quieren saber nada de él:

Seguramente nadie está a mi lado...

seguramente han dicho que me vaya. (63)

Siente que hasta sus parientes le han abandonado, porque tardan en venir en su ayuda:

César Callejo, parece

mentira que así tarden tus parientes. (152)

Y aunque esté en la compañía de otros, no le pueden sacar de su soledad: 
subes a acompañarme a estar solo. (73)

Esto le lleva al poeta a decir que su soledad constituye su mayor angustia:

El momento más grave de mi vida ha estado en mi mayor soledad (r47).

En Quisiera boy ser feliz... (64) el poeta experimenta el deseo de salir de la cárcel de su soledad y tomar contacto con el mundo exterior y con los demás hombres:

Quisiera hoy ser feliz de buena gana, ser feliz y portarme frondoso de preguntas,

abrir por temperamento de par en par mi cuarto, como loco, y reclamar, en fin,

en mi confianza física acostado, sólo por ver si quieren,

sólo por ver si quieren probar de mi espontánea posición, reclamar, voy diciendo, por qué me dan así tanto en el alma.

Quiere abrir las ventanas de su cuarto interior para dejar entrar el sol, la luz del mundo exterior. Quiere entablar conversación con otros, hacerles preguntas, interesarse por ellos. En su deseo de darse a otros y de que otros se den a él, es como una mujer que está acostada esperando a su amante. No entiende por qué los otros rechazan sus avances, por qué le causan pena tratándolo con indiferencia.

Esta indiferencia le lleva a sentir que todos se han vuelto contra él, que todos, colectiva e individualmente, le pegan y lo hacen sufrir:

Tú y él y ellos y todos, sin embargo, entraron a la vez en mi camisa, en los hombros madera, entre los fémures, palillos. (43)

Todos le pegan, dándole en los hombros con palos y clavándole astillas entre los huesos. Todos contribuyen a su dolor:

tú particularmente.

habiéndome influido; 
él, fútil, colorado, con dinero

y ellos, zánganos de ala de otro peso. (43)

Los amigos que le animan y le dan esperanzas infundadas; los ricos que gozan del lujo mientras que él sufre en la miseria; la masa anónima que se preocupa por otras cosas y es indiferente a su siuación; todos participan en su martirio.

Siente que la sociedad le es hostil y le oprime y que morirá

mientras el capitolio se apoye en mi intimo derrumbe y la asamblea en lanzas clausure mi desfile. (33)

La sociedad lo ha de desmoralizar y aplastar con todo el peso de sus edificios públicos; como una columna de soldados con lanzas lo ha de llevar a ser ejecutado. En otro poema prevé su muerte. Se ve morir, martirizado por los demás hombres, como un niño que es castigado injustamente por algo de lo cual es inocente:

César Vallejo ha muerto, le pegaban

todos sin que él les haga nada;

le daban duro con un palo y duro

también con una soga... (87)

Otro aspecto del abandono es la ausencia de Dios. En Poemas bumanos Dios no se manifiesta. Algunos poemas, como "Un pilar soportando consuelos..." (3I), dan a entender que la oración no recibe contestación. En "Acaba de pasar..." (ro3) nunca llega el Mesías que está esperando el poeta:

Acaba de pasar sin haber venido.

En el mundo de Vallejo el hombre está abandonado a sus propios recursos y no puede esperar auxilio de una fuente divina.

Coyné ha señalado que la poesía de Vallejo expresa "la inexplicable desnudez de la existencia". ${ }^{5}$ En una serie de poemas cuyo tema es. la miseria económica de los parias de la sociedad, el hombre está privado de las comodidades más elementales de la vida. En uno de estos. poemas un pobre se describe a sí mismo como un financiero que tendría que hacer bancarro:a si no fuera por un valor que todavía posee:

6 Ibid., p. 54 . 
Por último, sin ese buen aroma sucesivo, sin él, sin su cuociente melancólico, cierra su manto mi ventaja suave, mis condiciones cierran sus cajitas. (27)

Es un personaje chaplinesco, el hombre pequeño que se entrega a la fantasía en medio de su miseria. Pero hay una ironía cruel en su fantasía porque su único valor es un buen aroma, el olor de flores o de comida. Por su insignificancia este valor acentúa lo completa que es su privación.

El protagonista de "La rueda del hambriento" (40) ni siquiera tiene los medios para satisfacer la necesidad primaria de comer, y lamenta:

y ya no tengo nada, esto es horrendo.

La privación de los indigentes de "Traspié entre dos estrellas" (79) es tan absoluta que apenas tienen una existencia física:

Hay gentes tan desgraciadas, que ni siquiera tienen cuerpo... 20

El hombre vallejiano vive también en un vacío espiritual. En "Altura y pelos" (I24) el poeta afirma que sólo ha nacido, que existe y nada más, que lo único que conoce es la existencia despojada de meta, propósito o sentido:

¡Ay! ¡Yo que sólo he nacido solamente!

Otro poema refiere los tormentos de la introspección y da a entender que el pensar acerca de la vida sabotea toda creencia consoladora. E1 pensamiento es demoledor y deja al hombre sin valores en que apoyarse:

luego no tengo nada y hablo solo, reviso mis semestres

y para henchir mi vértebra, me toco. (II2)

El poeta se encuentra en un páramo espiritual, sin nada ni nadie en qué apoyarse. Revisa su vida, los meses y los años que se le han deslizado 
y los pocos que todavía le quedan. Tiene la espalda curvada por un sentimiento de derrota y siente que apenas existe, y tiene que tocarse para erguir la espalda y para convencerse de que todavía está vivo. lleva:

En "Ello es que..." (53) el poeta describe su casa y la vida que

Ello es que el lugar donde me pongo

el pantalón, es una casa donde

me quito la camisa en alta voz

y donde tengo un suelo, un alma, un mapa de mi España.

Su casa no es sino un suelo, una pieza vacía, y es la imagen del vacío. de su vida. Allí lleva una existencia rutinaria e intrascendente. Su vida es un círculo interminable de actos elementales -se viste y se desviste día tras día - y nunca pasa nada que la llene y le dé un sentido. En medio de este vacío él es un alma que vive angustiada. Una de sus pocas posesiones es un mapa de España, símbolo de su solidaridad con el resto de una humanidad sufriente.

Una técnica característica de Vallejo consiste en dar énfasis a algún objeto trivial. En el vacío en que vive el hombre tales objetos asumen importancia precisamente porque no tiene otra cosa, y por lo tanto se convierten en símbolos de su privación. Así el poeta insiste en la importancia de su patriótico peinado (42) y de sus momentáneos pantalones $(5 x)$, mientras que otros poemas hacen una enumeración de tales objetos:

$$
\begin{aligned}
& \text { un papelito, un clavo, una cerilla... (Ir7) } \\
& \text { este índice, esta cama, estos boletos. (I } 32 \text { ) } \\
& \text { mi zapato, su ojal, también su lodo } \\
& \text { y hasta el doblez del codo } \\
& \text { de mi propia camisa abotonada. (60). }
\end{aligned}
$$

De esta manera el poeta hace resaltar la absoluta desnudez de la existencia.

Otras características de los poemas subrayan esta desnudez. Paoli ha notado que en Poemas bumanos "manca... quasi completamente il mondo esterno all'uomo"? Sólo tres poemas describen el paisaje peruano en algún detalle, mientras que el ambiente parisiense se reduce a unas pocas alusiones. En la poesía de Vallejo no existe el mundo exterior de paisajes y edificios, y el hombre vallejiano vive sin un marco que

7 Roberto Paoli, Poesie, di César Vallejo, Lerici Editori, Milano, 1964, p. cxç. 
le dé un apoyo material y al cual pueda relacionar su vida. También es de notar la frecuencia con que se repiten los adverbios temporales boy y abora. En "Hoy le ha entrado una astilla..." (85), por ejemplo, boy se repite nada menos que ocho veces. Esta es una poesía irremediablemente arraigada en el momento presente. Para el hombre no existe la posibilidad de evasión o de apoyo en los recuerdos del pasado o en los sueños del futuro.

En Poemas bumanos el hombre se ve en una situación extrema: está privado de todas las barreras materiales y morales que suelen proteger a los hombres contra los rigores de la existencia. Por eso Coyné observa: "Toda la poesía de Vallejo nos aparece como inspirada por un sentimiento de desamparo y abandono" ${ }^{8}$ El hombre se encuentra frente a frente con la realidad, completamente desnudo, sin defensas de ninguna clase. Se encuentra en un mundo tenebroso y en las tinieblas intuye la presencia de algo hostil. Así los sentidos del poeta le señalan la presencia de la muerte detrás de la vida:

$$
\begin{aligned}
& \text { Y, en lógica aromática, } \\
& \text { tengo ese miedo ... de ser aquél, ése tal vez, } \\
& \text { a cuyo olfato huele a muerto el suelo". (69) }
\end{aligned}
$$

La tierra le huele a muerto, recordándole que él también ha de morir y que su carne podrida ha de contribuir a este olor.

En "El acento me pende..." (63) un ruido ominoso le inspira terror:
El acento me pende del zapato;
le oigo perfectamente
sucumbir, lucir, doblarse en forma de ámbar
y colgar, colorante, mala sombra.

No puede liberarse de este ruido amenazador porque le sigue como una bola encadenada a su pie. El ruido cambia de tono - a veces suena fuerte, a veces bajo, otras veces atenuado- y difunde un aire de mal augurio. El poeta siente que algo lo amenaza. Tiene la sensación de ser demasiado grande y demasiado expuesto y quisiera encogerse para desaparecer de la vista:

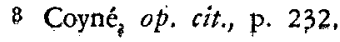




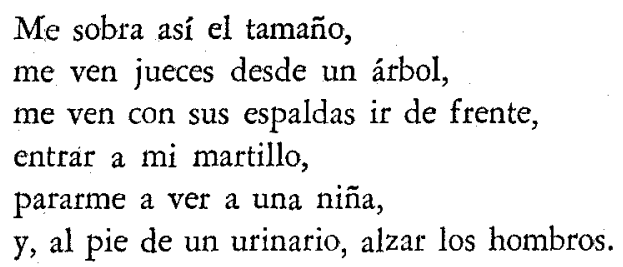

Tiene una sensación terrible de ser juzgado: los pájaros posados en las ramas de los árboles le parecen la encarnación de jueces inhumanos que lo vigilan, esperando el momento de condenarlo. De estos jueces inexorables no puede esperar ninguna misericordia: le dan la espalda y miran impasivos mientras tropieza con la desventura. Le observan hasta en los detalles más íntimos de su vida: cuando mira a una chica y cuando orina. Esta estrofa nos hace pensar en El Proceso de Kafka, donde el protagonista es prendido, juzgado y condenado sin saber siquiera cuál es su crimen. El poeta se siente amenazado por un poder implacable e incógnito del cual teme ser la víctima.

En los versos siguientes encontramos al poeta solo frente a esta potencia hostil. Se siente abandonado por los demás hombres que se niegan a ayudarle. Pero en medio de su abandono reacciona con orguIlo, afirmando que es fuerte y que no necesita ayuda:

Seguramente nadie está a mi lado, me importa poco, no lo necesito.

Sin embargo, en los últimos versos esta confianza queda destrozada:

Imperturbable! Imperturbable! Suenan

luego, después, fatídicos teléfonos.

Es el acento; es él.

La exclamación repetida expresa una seguridad algo forzada que no tarda en esfumarse al volver a manifestarse el ruido ominoso. Este ruido, semejante al zumbido de hilos telefónicos y que el lector también oye mediante una onomatopeya, parece señalar la presencia de alguna fuerza malévola, y en el último verso el poeta, solo e indefenso, lanza un grito de horror al sentirla avanzar sobre él. Como dice Coyné, "Los poemas aparecen ya como el reflejo de una impotencia fundamental ante un universo nocturno cargado de amenazas misteriosas"."

9 Ibid., p. 230. 
En resumen, el hombre, tal como aparece en Poemas bumanos, es pequeño e insignificante, frágil e indefenso. Vive en una soledad absoluta, aislado de los demás hombres. Su vida es completamente vacía: existe en un páramo espiritual sin ningún valor trascendental que llene su vida y le dé un sentido; vive en la miseria, privado de las comodidades materiales más elementales. Se encuentra frente a una realidad hostil sin defensas de ninguna clase. La orfandad es, en verdad, la condición del hombre vallejiano.

University of Liverpool,

James Higgins

University of Pittsburgh 
